\title{
STATISTICS EDUCATION RESEARCH IN MALAYSIA AND THE PHILIPPINES: A COMPARATIVE ANALYSIS
}

\author{
ENRIQUETA RESTON \\ University of San Carlos, Philippines \\ edreston@usc.edu.ph \\ SARAS KRISHNAN \\ University of Malaya, Malaysia \\ saraskrishnan@yahoo.com \\ NORAINI IDRIS \\ University of Malaya, Malaysia \\ noridris@um.edu.my
}

\begin{abstract}
This paper presents a comparative analysis of statistics education research in Malaysia and the Philippines by modes of dissemination, research areas, and trends. An electronic search for published research papers in the area of statistics education from 2000-2012 yielded 20 for Malaysia and 19 for the Philippines. Analysis of these papers showed that most were primarily empirical research published in national refereed journals or in conference proceedings. Statistics education research in Malaysia has focused on integration of technology and on affective aspects of statistics learning. In the Philippines, studies have investigated university-level statistics pedagogy, statistics academic programs and teachers' professional development. Implications for future statistics education research and teaching practice in these two countries are identified.
\end{abstract}

Keywords: Statistics education research; Publications; Research Areas

\section{INTRODUCTION}

\subsection{STATISTICS EDUCATION RESEARCH FROM A GLOBAL PERSPECTIVE}

Over the past two decades, statistics education research literature has rapidly expanded along with the increased recognition of the importance of statistics education in this modern information age. Improving the teaching and learning of statistical concepts at all levels of education has been extensively investigated in the literature. Batanero (2007) contended that statistics pedagogy is a research area of increasing interest among mathematics and statistics educators and the area has also received contributions from researchers in psychology and other disciplines with diverse educational backgrounds and training. MacGillivray and PereiraMendoza (2011) noted the considerable discussion, research and developments in statistics education during the past two decades to meet the challenges of facilitating the learning of statistical thinking and reasoning. There is also an expanding literature on statistical literacy as an overarching goal for introductory college statistics courses (delMas, 2002; Rumsey, 2002; Wallman, 1993). Gal (2002) defines statistical literacy as "the ability to interpret, critically evaluate, and communicate about statistical information and messages." (p. 1)

From a global perspective, statistics education research has taken different forms and directions in various parts of the world. Starting in 1990s, there has been a reform of statistics education that shifted the focus of teaching and learning from mathematical procedures to an emphasis on statistical knowledge construction and forming connected and useful

Statistics Education Research Journal, 13(2), 218-231, http://iase-web.org/Publications.php?p=SERJ (C) International Association for Statistical Education (IASE/ISI), November, 2014 
understanding of statistics. This includes investigations of students' conceptual understanding, the use of active learning strategies and real data in teaching and learning statistics, and the integration of technology into statistics education (Chance, Ben-Zvi, Garfield, \& Medina, 2007; Franklin \& Cooley, 2002; Glencross \& Binyavanga, 1996; Rossman \& Short, 1995). While research on the use of technology in pedagogy, curriculum development, and student learning has continued to dominate the statistics education literature, we see the expansion of statistics education research to other types of research questions which include conceptualizing the construct of statistical literacy, thinking and reasoning as the overarching goal of statistics education (e.g., Gal \& Garfield, 1997; Rumsey, 2002; Watson \& Callingham, 2003), investigation of affective components in learning statistics (e.g., Gal, Ginsburg, \& Schau, 1997; Schau, 2003), and the expansion of the subject of research to involve not just students of statistics but also teachers of statistics and curriculum (e.g., Eichler, 2011; Verschut \& Bakker, 2010).

As the goals and approaches in statistics education have shifted in focus from the traditional, formula-based procedures to statistical literacy, thinking and reasoning with data in context (Gal \& Garfield, 1997; Rumsey, 2002) along with the rapidly increasing use of technological resources that foster student learning, many statistics educators have investigated teaching practice to document evidence of change in alternative modes of instruction in line with these goals. Research on students' statistical learning has tended to focus on comparisons of instructional modes such as traditional lecture versus technology-rich learning environments (e.g., Tawil et al., 2011, 2012), identifying students' misconceptions (e.g., Fidler \& Cumming, 2005; Link, 2002), and factors contributing to students' achievement in statistics (e.g., Hong, 2002; Mohamed, Sahari, Judi, \& Wook, 2012).

From the 1990s onwards, various projects have been documented in the literature on statistics education reform efforts. Many of these projects focused on the role of technology in statistics education and the design of teaching-learning experiences that optimize the use of technology. Cobb (1993), for instance, described twelve projects funded by the National Science Foundation (NSF) in the United States on developing curricular resources for teaching introductory statistics courses using real data sets, hands-on laboratory activities and computer simulations. Following Cobb's lead, Hall and Rowell (2008) examined 27 NSF projects, funded from 1993 to 2004, and described how they addressed the Guidelines for Assessment and Instruction in Statistics Education (GAISE) for introductory statistics courses. The GAISE recommendations (American Statistical Association, 2005) provide a framework for statistics education aimed at enabling students to achieve statistical literacy, both for their personal lives and in their careers (Metz, 2010). Outside the United States, various reform efforts in statistics education in Australia, New Zealand and the United Kingdom (as well as other parts of Europe) have generated various research papers that reported the impact of these projects on student learning. Authors from these four English-speaking countries accounted for the majority (64\%) of papers published in SERJ from 2002 to 2009 (Zieffler et al., 2011).

The advancement of statistics education research is supported by well-known international bodies that provide expert help and a wealth of resources for educators and researchers. The International Statistical Institute (ISI) and one of its sections, the International Association for Statistical Education (IASE), promote and assist the development of statistics education throughout the world. ISI's mission includes facilitating collaboration among diverse groups and organizations having statistical interests, and developing new initiatives to maintain leadership of an evolving discipline in changing environments. It aims particularly at connecting international statistical societies with specific focus on the developing nations. Statistics education research has also gained more prominence at international conferences of the ISI and the IASE. The International Conference on Teaching Statistics (ICOTS) of IASE and the International Congress on Mathematics Education (ICME) are popular platforms for statistics educators and researchers to exchange ideas and advance the field of statistics education. The sustained online publication of research articles in professional journals such as Journal of Statistics Education (JSE) of the American Statistical Association, Statistics Education Research Journal (SERJ) of IASE and Technology Innovations in Statistics 
Education (TISE) of the University of California in Los Angeles also attest to the expanding growth of statistics education research literature.

The ongoing efforts of these international bodies to globalize statistics education have led to emerging literature on the internationalization and globalization of statistics education. For instance, Smith, Reid, and Petocz (2009) applied a model of internationalization to examine papers presented at ICOTS7. The results showed that of 300 invited and contributed papers spanning a wide range of topics, the majority $(83 \%)$ of the papers do not mention internationalization; nevertheless, the fact that these papers were presented at an international conference involving delegates from many countries points toward the notion of internationalization of statistics education. This paper is relevant to the present study since the comparative analysis of statistics education research in Malaysia and the Philippines points out the need to consider the international dimensions of statistics education without losing sight of the local contexts.

An important reflection made in this paper is the predominance of English as the main language in most developed countries and thus the language of communication in most statistics education conferences and publications. This phenomenon creates a sort of restriction in terms of publishing papers and using materials and resources for communities of statistics educators and researchers in less-developed countries where English is not the first language. In addition, most developing countries have limitations on obtaining and using advanced technologies, and the advancement of technology has been crucial in taking statistics education to greater heights. Thus, there is a need for statistics education research that investigates the balance between access and impact on learning statistics of these technological innovations, particularly in developing countries. It is noted that many of the studies on technological innovations describe the scenario of more developed, industrialized countries in the West, and very little has been written on statistics education, particularly at school level and in developing countries.

Moreover, despite fast-growing development in the global statistics education research scenario, research in this area is still emerging in most Asian countries, including most countries of Southeast Asia or the ASEAN (Association of Southeast Asian Nations) region. Nevertheless, statistics education research is gaining visibility in this region in countries such as Malaysia and the Philippines, the subjects of the current investigation. Factors influencing and contributing towards the development of statistics education in Malaysia and the Philippines are different as are the research interests in these countries.

\subsection{STATISTICS EDUCATION IN MALAYSIA AND THE PHILIPPINES}

The direction and development of statistics education among developing countries depends on many factors, such as their socio-economic conditions, political stability and philosophy of education held by the educational system in these countries. This section provides a brief review and discussion of statistics education in Malaysia and the Philippines. A discussion of the types of research in statistics education undertaken in these two countries must be grounded in their contextual realities in order to provide a clearer picture upon which research in these two countries is based. The aim of this paper is to make a comparative analysis of the statistics education research undertaken in these two countries and provide future directions for filling the gaps and forging possible collaborative studies between these countries.

Malaysia Statistics education in Malaysia has to be discussed from the perspective of the mathematics education domain because statistics is still, for the most part, viewed there as a component of the mathematics syllabus. On the global platform, statistics education reform coupled with rapid advances in technology has elevated statistics to be on par with mathematics education instead of being a part of mathematics education. This has influenced the emergence of statistics courses at the undergraduate and postgraduate levels in higher education institutions in Malaysia. Although not yet extensive, the importance of statistics education is slowly making its mark in the Malaysian education system. However, in secondary schools and in a majority of undergraduate courses not specializing in statistical studies, statistics and probability are taught as one topic of mathematics courses. This factor has led students to have 
an opinion of statistics as a computational rather than a practical subject in the sense that students focus on statistical formulas and calculations with little or no understanding of the reasons for using a statistical procedure or the meaning of the results of a statistical analysis. As a practical subject, statistics could be learned and appreciated in terms of its broad range of applications in various contexts rather than in terms of its formulas and calculations.

From a wider perspective, the integrated mathematics curriculum which was implemented in the late 1980s approached the teaching and learning of mathematics from problem-solving approaches (Zanzali, 2003). Some of the pedagogical considerations of the integrated mathematics curriculum are the integration between theoretical knowledge and practical applications, and the integration of mathematics with other branches of knowledge. In general, the integrated curriculum shaped the contents of mathematics in three important areas: number, shape, and relations (Zanzali, n.d.). It appeared that statistics and probability are not seen as important in the mathematics curriculum, although they were included in the syllabus guide that was provided to all teachers. Thus, the authors feel that the importance and significance of statistics and probability in the mathematics curriculum, and subsequently the importance and significance of statistics education to the Malaysian community, is not yet clearly defined or highlighted in curriculum development.

The Philippines Statistics education in the Philippines is viewed from two perspectives: (1) the education of future statistics practitioners through formal higher degrees in statistics, and (2) the teaching of statistics to the general population of students across all levels as part of the mathematics curriculum at school or as stand-alone courses at tertiary level. Bersales (2004) provided a historical perspective on statistics education in the Philippines with a focus on the formal training of statisticians in both undergraduate and graduate programs. She reported that profiling faculty and schools that offer academic programs in statistics indicates that there is still a dearth of trained teachers. Nebres (1998, as cited in Bersales, 2004) also noted the lack of sufficient numbers of talented undergraduate students in the mathematical sciences. The limited number of statistics majors at the undergraduate level translated to a lack of students majoring in statistics at the graduate level.

For the statistics education of non-majors, introductory statistics courses are being offered in many academic programs as stand-alone courses at tertiary level, while basic concepts of probability and statistics are taught as part of the mathematics curriculum at school level (Reston \& Bersales, 2011). However, statistics education in the Philippines is plagued with problems: lack of qualified teachers, a lack of locally-produced statistics books and educational materials, inadequate facilities such as computer laboratories, software and other teaching aids, and mechanistic teaching methods that do not enhance the teaching of statistics (David \& Maligalig, 2006; Reston \& Bersales, 2011; Tabunda, 2006). Many reform efforts have been made by different stakeholders in the country to improve the teaching and learning of statistics. The Philippine Statistical Association and the Philippine Statistical System have increasingly provided support for the academe in statistics instruction. Reston and Bersales (2011) reported these advocacy efforts, such as the review of locally-written statistics textbooks, grants for writing reference books, training for college teachers of basic statistics, and holding of forums to present research in statistics education. Moreover, in consideration of all these reform efforts, there is the added challenge of teaching statistics at Senior High School level in the light of the recent $K$ to 12 Basic Education reform in the Philippines which began June 2012. This education reform, which expanded the basic education cycle from 10 to 12 years, has now recognized the study of statistics as a stand-alone course in the Senior High School mathematics curriculum (Department of Education, 2012). Consequently, the current reforms in the General Education curriculum at the tertiary level call for creative ways to teach college statistics from interdisciplinary, holistic perspectives (Commission on Higher Education, 2012).

\section{RESEARCH QUESTIONS AND METHODS}

The goal of this study is to analyze and categorize research publications on statistics education in Malaysia and the Philippines in order to investigate trends and make suggestions for future developments. Comparisons are made between the two countries in terms of modes 
of dissemination, research areas, and trends. The findings may serve as baseline information for guiding directions towards improving the scale and quality of statistics education research in these two countries. More precisely, this paper seeks to address the following research questions:

1. What publications on statistics education were generated by authors from Malaysia and the Philippines within the period 2000 to 2012 ?

2. What areas of statistics education research were addressed in these published papers?

3. What commonalities, differences, and trends exist in these published papers?

The population of interest in this study comprises all published papers on statistics education research by authors from Malaysia and the Philippines for the period 2000 to 2012. The criteria for inclusion are the following: (1) the papers may be original empirical studies or theoretical/conceptual papers based on secondary sources and existing literature, (2) they may be published in a professional journal or a professional conference proceedings, either national or international, and (3) they may be single-authored or multiple-authored by citizens of these two countries. For multiple-authored studies, foreign collaborators may be co-authors provided at least one of the authors is a citizen in either of these two countries.

For Malaysia, published papers were first identified from a wide electronic search using Google by typing relevant keywords such as Malaysia and statistics education. and then it is narrowed down to publications related to this study. This indicated that such research most often appears in a small number of journals, such as Procedia Social and Behavioral Sciences, The Internet and Higher Education, and Australian Journal of Educational Technology. Other papers were identified from the reference and citation lists of the initial collection. Some of these papers appeared in non-statistics journals, for instance Hong, Lai, and Holton's (2001) investigation of web-based learning for a group of statistics students.

For the Philippines, an electronic search of papers published in local journals was carried out through the Philippine E-Journals website (http://ejournals.ph), an expanding collection of about 100 academic journals published by higher education institutions in the country, made accessible globally through a single web-based platform. Aside from this, an electronic search was made in journals indexed by Scopus and the International Scientific Index (ISI), and through a wider Google search. Further searching was done for journals and conference proceedings published by professional associations such as the Statistics Education Research Journal (SERJ), the Journal of Statistics Education (JSE), and Technology Innovations in Statistics Education (TISE).

Data were analyzed by reading the papers collected and identifying the publication information and the research areas. The publication information includes type of paper, authorship, and publication type. The papers are divided into two groups based on the publication year: 2001-2006 and 2007-2012. Nine research areas were identified from these papers: assessment, curriculum development, academic programs, teaching and learning at school level, teaching and learning at university level (undergraduate or graduate), students' learning and achievement, attitudes and other affective factors, teachers' professional development, and integration of technology.

Zieffler et al. (2011) investigated papers published in SERJ, and their approach also provided ideas for the current study. They cited the methods of content analysis, meta-analysis and text mining for analyzing a body of research, and applied content analysis to classify the SERJ papers from 2001 to 2009. Their model provided some basis for classifying the papers from Malaysia and the Philippines with a focus on author information and research areas. Metaanalysis is not appropriate for this study since meta-analytic methods focus on quantitative studies that address a single broad question (Rosenthal, 1984 as cited in Zieffler et al., 2011) while this paper analyses a broad spectrum of quantitative and qualitative studies addressing various research questions in statistics education.

\section{RESULTS}

The search for published statistics education research papers from Malaysia and the Philippines for the designated period yielded a total of 20 papers for Malaysia and 19 papers for 
the Philippines. The papers are first categorized based on the publication and dissemination information, and then based on the research area in order to make comparisons of statistics education research between these two countries. The results are reported descriptively as counts and percentages in Table 1 and Table 2.

\subsection{STATISTICS EDUCATION PUBLICATIONS IN MALAYSIA AND THE PHILIPPINES}

The publication details for the statistics education papers generated from Malaysia and the Philippines are summarized in Table 1 in terms of the type of paper, authorship, publication type and year of publication.

Table 1. Statistics education research publications in Malaysia and the Philippines (2001-2012)

\begin{tabular}{lcc}
\hline Publication Information & $\begin{array}{c}\text { Malaysia } \\
(n=20) \\
\text { Count (\%) }\end{array}$ & $\begin{array}{c}\text { The Philippines } \\
(n=19) \\
\text { Count (\%) }\end{array}$ \\
\hline $\begin{array}{l}\text { Type of Paper } \\
\text { Empirical Research }\end{array}$ & $\begin{array}{r}19(95) \\
1(5)\end{array}$ & $15(79)$ \\
$\quad$ Theoretical/Conceptual Essays & & $4(21)$ \\
\hline Authorship & $3(15)$ & $12(63)$ \\
$\quad$ Single author & $15(75)$ & $7(37)$ \\
$\quad$ Multiple authors within the country & $2(10)$ & - \\
$\quad$ Multiple authors with international collaboration & & \\
Publication Type & $13(65)$ & $7(37)$ \\
$\quad$ Peer-reviewed professional journal & $7(35)$ & $11(58)$ \\
$\quad$ Professional conference proceedings & - & $1(5)$ \\
$\quad$ Book chapter & $5(25)$ & $9(47)$ \\
\hline Year of Publication & $15(75)$ & $10(53)$ \\
2001-2006 & & \\
2007-2012 & &
\end{tabular}

Malaysia For Malaysia, most published papers were empirical research (95\%), with only one paper representing theoretical research or conceptual essay. Most of the papers were written by multiple authors within the country $(75 \%)$, as opposed to a single author $(15 \%)$ or multiple authors with international collaboration (10\%). In terms of the publication type, the majority were published in peer-reviewed journals $(65 \%)$ and the others in professional conference proceedings (35\%). As expected from increasing development of statistics education at all levels, more studies were undertaken from 2007-2012 (75\%) than 2001-2006 (25\%). Fewer papers were published in conference proceedings during both periods: three in peer-reviewed journals and one in professional conference proceedings for 2001-2006, and ten in peer-reviewed journals and five in professional conference proceedings for 2007-2012.

While five of the papers were published in the journal Procedia Social and Behavioral Sciences, only one paper was published in each of the other journals, namely: Australian Journal of Educational Technology, The Internet and Higher Education, Educational Technology and Society, Science and Mathematics Journal, Journal of Quality Measurement and Analysis, Computers and Education, IBIMA Business Review and Asian Social Science. Of the seven papers published in professional conference proceedings, three were published in the proceedings of the International Conference on Science and Mathematics Education, and one paper each was published in the proceedings of the National Conference on Graphing Calculators, Integrating Technology in the Mathematical Sciences and WSEAS International Conference on Multivariate Analysis and its Application in Science and Engineering, and the Roundtable Conference of the IASE.

The Philippines For the Philippines, most of the published papers were empirical research $(79 \%)$ and single-authored (63\%), and there was no paper with international author 
collaboration. More papers were published in professional conference proceedings than in peerreviewed journals. The IASE conferences provided the most popular venue of dissemination, with seven of the 11 papers from the proceedings of ICOTS and other IASE conferences. Also, the sole book chapter publication was an output of the Joint Study Conference of the IASE and the International Commission on Mathematics Instruction (ICMI). There were only two papers from proceedings of the ISI Sessions (now World Statistics Congress) of the ISI and another two papers from the National Convention on Statistics in the Philippines. Of the seven journal papers, four were published in The Philippine Statistician of the Philippine Statistical Association (PSA), two papers in the IAMURE Journal of the International Association of Multidisciplinary Research, and one paper in The Asia-Pacific Education Researcher. The publications were almost evenly divided between the early period (47\%) and the later period (53\%). There were no papers from Filipino authors found published in SERJ or JSE for the period included in this study. Moreover, the two papers which were first published in conference proceedings and later in peer-reviewed journals were counted at the higher level, as peer-reviewed journal publications.

\subsection{RESEARCH AREAS OF PAPERS FROM MALAYSIA AND THE PHILIPPINES}

Nine areas of research in statistics education were identified from the published papers from these two countries. Descriptive analysis of the distribution of papers in the two countries is shown in Table 2 and reveals some interesting differences in the research areas favored (and neglected) by each country.

Table 2. Research Publications in Malaysia and the Philippines by Areas (2001-2012)

\begin{tabular}{lcc}
\hline Research Area & $\begin{array}{c}\text { Malaysia } \\
(n=20) \\
\text { Count (\%) }\end{array}$ & $\begin{array}{l}\text { Philippines } \\
(n=19) \\
\text { Count (\%) }\end{array}$ \\
\hline Assessment in statistics education & $1(5)$ & $1(5)$ \\
Curriculum development & $1(5)$ & $1(5)$ \\
Statistics academic programs & - & $4(21)$ \\
Statistics teaching and learning at school level & $1(5)$ & $1(5)$ \\
Statistics teaching and learning at university & $2(10)$ & $8(42)$ \\
Students' learning/achievement in statistics & $3(15)$ & $1(5)$ \\
Students' attitudes towards statistics, affective factors & $5(25)$ & - \\
Statistics teachers' professional development & - & $2(11)$ \\
Technology integration in statistics education & $7(35)$ & $1(5)$ \\
\hline
\end{tabular}

Malaysia For Malaysia, the seven publications on 'technology integration in statistics education' may be divided into two groups: web-based learning environment (three papers) and the use of graphics calculator (four papers). Research in both categories spanned the twelveyear period. The five publications on 'students' attitudes towards statistics and other affective factors' focused on identification of student profiles (four papers), with another paper highlighting the use of technology. This shows that there is an overlap of research areas. For example, this latter paper reported research by Kor and Lim (2004) on attitudes of undergraduate students in an innovative introductory statistics course using graphics calculators. Although the dominant research interest in their paper can be classified as students' attitudes, there is also a strong focus on the integration of technology.

On the other hand, studies showing a specific research focus could be placed into different categories. For instance, a publication on different teaching methods by Ghani and Idris (2009) is focused on 'students' learning and achievement in statistics', while a paper by Tawil et al. (2011) comparing learning in lectures or by e-learning was categorized as 'statistics teaching and learning at university level'. The three publications on 'students' learning/achievement in statistics' involved learning with the aid of technology (Hong, 2002), different teaching styles (Ghani \& Idris, 2009), and factors contributing towards students' achievement in statistics (Mohamed et al., 2012). Two further publications on 'statistics teaching and learning at 
university' involved different teaching styles (Tawil et al., 2011) and statistics anxiety among undergraduate students (Hassan, Ismail, Ghazali, Gindana, \& Wan Jaafar, 2011).

The Philippines In the Philippines, the research areas showed a different focus. The largest group comprised eight papers on 'statistics teaching and learning at university', undergraduate or graduate level. Some of these papers investigated the effect of different teaching approaches and methods on improving student learning and achievement; for example, problem and activity-based approaches (Herrera, 2011), geometric tools for teaching probability (Limjuco, 2012), and teaching experiments (Almeda \& Barrios, 2010). There were also papers that surveyed and evaluated the quality of textbooks used in introductory college statistics courses (David \& Maligalig, 2006) and the preparation and qualification of statistics teachers in higher education (Tabunda, 2006). Another three papers dealt with teaching graduate statistics courses, focusing on assessment of statistical literacy among graduate students (Reston, 2005), teaching for statistical literacy in research (Reston, 2007), and assessment of graduate students' conceptions of statistical inference (Jala \& Reston, 2010).

This group was followed by four papers on 'statistics academic programs'. This included surveys of statistics academic programs in the Philippines and the role of the academe in statistical workforce development of the country (Bersales, 2004, 2006), and a study on teaching statistical consulting (Barrios, 2010). Also, a conceptual paper by David (2009) argued that fundamental differences in the application of statistics and mathematics require the inclusion of statistics as a separate discipline from mathematics in the education system.

On the other hand, there were two papers on statistics teachers' professional development (Reston \& Bersales, 2011; Reston, Jala, \& Edullantes, 2006). There is only one paper each on 'assessment in statistics education', 'curriculum development,' 'statistics teaching at school level', and 'technology integration in statistics education'. The lone paper that focused on integration of technology (Reston, 2012) is a conceptual paper that proposed an outcome-based framework for technology education in higher education statistics. There was no paper found that focused primarily on empirical investigation of students' achievement in integrating technology in teaching statistics and on investigation of attitudes and other affective factors in the teaching and learning of statistics in the Philippines.

However, there are overlaps in classifying papers by research areas. For instance, the paper by Prado and Gravoso (2011) was classified under 'statistics teaching and learning at school level', but a closer review revealed that the authors discussed integration of technology - video recordings - in applying anchored instruction. Despite this, the paper was not classified under 'technology integration in statistics education' since the title and abstract did not focus on thisthe use of videos was just one means to implement anchored instruction.

\subsection{COMMONALITIES, DIFFERENCES, AND TRENDS}

A review of the published papers in these two countries shows that there are a few commonalities across these articles but some differences. The search yielded only a small number of published articles in statistics education produced by researchers in these two countries over a span of 12 years, a similar number in each country. The majority of these papers were empirical studies. Most papers were published in local refereed journals or conference proceedings, and no published article was found in refereed international journals in statistics education, such as SERJ and JSE. The theoretical constructs being investigated focused on statistics teaching and learning at the tertiary level (10 papers in total, most from the Philippines) and integration of technology in statistics pedagogy (8 papers, most from Malaysia), followed by a smaller group on attitudes and affective factors ( 5 papers, all from Malaysia). Further analysis of the papers revealed that the research questions being pursued by the researchers required methods ranging from basic case studies and descriptive surveys to experimental studies.

The most notable differences were the type of authorship, mode of publication and the research areas. Most papers published in Malaysia were multiple-authored within the country and in peer-reviewed professional journals. On the other hand, most papers from the Philippines were single-authored and published in conference proceedings. The top three 
research areas in Malaysia were technology integration in statistics education, students' attitudes towards statistics and other affective factors, and students' learning and achievement in statistics. However, these areas were pursued the least by authors from the Philippines, who focused more on statistics teaching and learning at university level, followed by statistics academic programs, and teachers' professional development, areas that were least pursued by Malaysian researchers.

The results indicate that there is opportunity for research in the more-neglected areas in each country. In particular, there is further need in both countries for research on statistics education at school level, maybe including aspects of assessment and curriculum development. It could also be useful to expand into research areas that link epistemology to other constructs in teaching and learning statistics (such as statistical literacy, thinking and reasoning, and students' and teachers' attitudes and beliefs toward learning statistics) in contextualized settings that reflect the cultural perspectives of these two countries and Asian culture in general.

\section{DISCUSSION AND IMPLICATIONS}

\subsection{DISCUSSION}

The comparative analysis of statistics education research in Malaysia and the Philippines contributes some interesting and diverse findings. The research areas identified from the papers are indicative of the state of statistics education in these countries.

Two themes dominated the papers produced by Malaysian authors, accounting for $60 \%$ of the published papers surveyed. The themes are integration of technology in statistics teaching, and investigation of attitudes towards statistics and other affective measures. The first theme is indicative of a growing interest in Malaysia in alternative modes of instruction that optimize the use of technology for learning statistics. Chance et al. (2007) maintained that while the use of technology to facilitate and improve the learning of statistical concepts is well-supported by research, effective utilization of technology requires thoughtful and deliberate planning and a system to evaluate existing software critically from the perspective of educating students.

By contrast, in the Philippines there is a limited number of empirical studies found that investigated technology integration in statistics instruction. This indicates the need to investigate the extent to which statistics education there has integrated contemporary technology, a feature that has changed the global landscape of statistics education and research over the past two or three decades. Similarly, there were no empirical studies in the Philippines that dealt with affective factors in the teaching and learning of statistics. Gal, Ginsburg, and Schau (1997) stressed the importance of monitoring students' attitudes and beliefs, as these may affect their learning of statistics. There is also an expanding global literature exploring teachers' attitudes and beliefs in relation to statistics education and Batanero (2011) considers this a priority area of research. Understanding statistics teachers' attitudes and belief systems could enhance the preparation of teacher educators and future teachers of statistics.

Research areas represented by authors from the Philippines focused on the teaching of statistics at university level, teachers' professional development, and statistics academic programs for preparing statisticians and practitioners. Statistics education research in these areas contributes to evaluating and validating the various reform efforts and the instructional interventions introduced to improve statistics teaching and learning. These research areas are indicative of the focus on higher education and the important role of the teacher and the curriculum for successful statistics pedagogy. Tishkovskaya and Lancaster (2012) contended that the impact of statistics education research has started to change course content and structure at the university level, in both introductory and advanced statistics courses during the $21^{\text {st }}$ century. However, this remains to be investigated for statistics teaching at universities in the Philippines.

On the other hand, the need for professional development frameworks for preparing mathematics teachers to teach statistics at school level in both the Philippines and Malaysia is another area of concern. Reston and Bersales (2011) pointed out the lack of emphasis on statistics education in the in-service professional development of mathematics teachers at 
school level and the need for coherent instructional design framework for teacher training in statistics. They proposed the application of research-based professional development projects for mathematics teachers, using, for example, the 'Statistical Reasoning Learning Environment' (SRLE) framework (Garfield \& Ben-Zvi, 2008) to enhance the preparation of mathematics teachers in teaching statistics within the mathematics curriculum at the school level. While this paper focused on the Philippines context, it would seem to be equally applicable to the situation in Malaysia.

While statistics educators and researchers in both Malaysia and the Philippines have investigated teaching practice to document evidence of change following alternative modes of instruction, there is a need for further research to identify effective instructional innovations and to document evidence of the impact of various interventions and factors on students' learning of statistics.

\subsection{LIMITATIONS}

We identified several limitations in the identification, classification, and analysis of statistics education research papers from Malaysia and the Philippines. The methodology relied primarily on a web-based search of papers from journals, conference proceedings and other sources. It is possible that some papers that were published only in print were missed. There were attempts, however, to search print journals and other sources through publications by professional statistical associations, as in the case of articles published in The Philippine Statistician, a print journal publication of the PSA for the earlier time period within the study.

We limited the categorization of the papers into explicit classifications based on factual data such as the type of publications, types of authorship, year published, and research areas. An attempt to classify papers by theoretical framework used was not pursued since several papers did not explicitly indicate this. The classification of papers by research area was to some extent problematic and some possible overlaps were identified. Moreover, the primary basis of the classification was the analysis of the key constructs mentioned explicitly in the titles of the papers. In consideration of these limitations, the results should be viewed as descriptive and not generalizable. However, the information generated for this paper provides a picture of the statistics education research landscape in these two countries which is rich in implications for future research and educational practice.

\subsection{IMPLICATIONS FOR FUTURE STUDIES}

Several key implications emerge from the collective review of these papers and the survey of their contributions to the statistics education literature. Firstly, the research areas investigated in the papers reviewed were limited and there is need for statistics education researchers in these two countries to contribute more substantially to the expanding statistics education literature that includes a balance of both global and local contexts. Along this line, Smith, Reid, and Petocz (2009) pointed out the importance of investigating the notion of internationalization within statistics education, particularly from the perspective of developing countries as a means of empowering their citizens to cope with the contemporary challenges of globalization. This could be one area that researchers from these two countries can begin to investigate within international collaborations, such as that of the Asia-Pacific Economic Cooperation (APEC) Open Borders in 2015. This project aims to promote a knowledge-based economy through enhanced cross-border education, science and technology education, and skills development for the $21^{\text {st }}$-century, as a key to developing the competitiveness of industries and achieving growth in the Asia-Pacific region.

Secondly, it was apparent that the research papers utilized an array of methodological approaches (including case studies, survey research, and experimental studies), but with a focus on quantitative research. While quantitative research approaches have been popular for several decades, international contributions to statistics education research have recently moved to include qualitative methods in order to develop a richer understanding of personal epistemology in the teaching and learning of statistics. Thus, there is need to expand statistics education 
research in Malaysia and the Philippines to include more contextualized and in-depth qualitative studies on how students learn statistics and how teachers develop their capacities to teach statistics within the cultural context of Asian societies.

Further, this paper lays the groundwork and direction for future research in statistics education in these two countries and in the ASEAN region at large. This exploration of statistics education literature in Malaysia and the Philippines will help future researchers build on existing research and chart new areas to explore. It can help to expand the focus of research in these countries to other areas or objectives across all levels of statistics education, including the preparation of statistics teachers and connections to classroom practice. Much work remains to address the issues that concern statistics educators and researchers in Malaysia and the Philippines. There is a need for more international collaboration and institutional support in order to advance investigations on technology integration in teaching and learning statistics, particularly in the case of the Philippines. There is also a need for more collaborative research to create models and frameworks for statistics education that capture both global and local realities, and to advance their contribution to the global statistics education literature by publishing the research in international refereed professional journals.

\section{REFERENCES}

Almeda, J., \& Barrios, E. (2010). Teaching statistics using experiments. In C. Reading (Ed.), Data and Context in Statistics Education: Towards an evidence-based society. Proceedings of the $8^{\text {th }}$ International Conference on Teaching Statistics. Voorburg, The Netherlands: International Statistical Institute.

[Online: http://iase-web.org/documents/papers/icots8/ICOTS8 10A2 ALMEDA.pdf]

American Statistical Association (2005). Guidelines for assessment and instruction in statistics education: College report. Alexandria, VA: Author.

Barrios, E. (2010). Teaching of statistical consulting in the Philippines. The Philippine Statistician, 59, 103-107.

Batanero, C. (2007). Special Issue: Emerging research in statistics education. International Electronic Journal of Mathematics Education, 2(3), 107-109.

[Online: http://www.iejme.com/032007/editorial.pdf]

Bersales, L. G. (2004). The role of the academe in the continuing development of the statistical manpower of the Philippine Statistical System: The UP School of Statistics perspective. Proceedings of the 9th National Convention on Statistics (pp. 1-10). Manila, Philippines.

Bersales, L. G. (2006). Academic programs in statistics in the Philippines. The Philippine Statistician, 55(3/4), 1-13.

Chance, B., Ben-Zvi, D., Garfield, J., \& Medina, E. (2007). The role of technology in improving student learning of statistics. Technology Innovations in Statistics Education, $1(1), 1-26$.

[Online: http://escholarship.org/uc/item/8sd2t4rr ]

Cobb, G. W. (1993). Reconsidering Statistics Education: a National Science Foundation Conference. Journal of Statistics Education, 1(1).

[Online: http://www.amstat.org/publications/jse/v1n1/cobb.html ]

Commission on Higher Education (2012). The Revised General Education Program: Holistic understandings, intellectual and civic competencies. CHEd Technical Panel on General Education, Quezon City, Philippines: Author.

David, I. P. (2009). How is statistics different from mathematics? And why is the distinction important? The Philippine Statistician, 58, 105-110.

David, I. P., \& Maligalig, D. S. (2006). Are we teaching statistics correctly to our youth? The Philippine Statistician, 55(3-4), 1-28.

delMas, R. C. (2002). Statistical literacy, reasoning and learning: a commentary. Journal of Statistics Education, 10(3).

[Online: http://www.amstat.org/publications/jse/v10n3/delmas discussion/html]

Department of Education (2012). The K to 12 Basic Education Program. Pasig City, Philippines. 
Eichler, A. (2011). Statistics teachers and classroom practices. In C. Batanero, G. Burrill, \& C. Reading (Eds.), Teaching statistics in school mathematics - Challenges for teaching and teacher education: A Joint ICMI/IASE study (pp. 175-186). Dordrecht, The Netherlands: Springer Science +Business Media.

Fidler, F., \& Cumming, G. (2005). Teaching confidence intervals: Problems and potential solutions. Paper presented at the 55th Session of the World Congress of the International Statistical Institute, Sydney, Australia.

[Online: http://iase-web.org/documents/papers/isi55/Fidler-Cumming.pdf ]

Frankin, L. A., \& Cooley, B. J. (2002). An experiential approach to integrating ANOVA concepts. Journal of Statistics Education, 10(1).

[Online: http://www.amstat.org/publications/jse/v10n1/datasets.franklin.html ]

Gal, I. (2002). Adults' statistical literacy: Meanings, components, responsibilities. International Statistical Review, 70(1), 1-24.

Gal, I., \& Garfield, J. (1997). Curricular goals and assessment challenges in statistics education. In I. Gal \& J. B. Garfield (Eds.), The assessment challenge in statistics education (pp. 113). Voorburg, The Netherlands: IOS Press.

Gal, I., Ginsburg, L., \& Schau, C. (1997). Monitoring attitudes and beliefs in statistics education. In I. Gal \& J. B. Garfield (Eds.), The Assessment Challenge in Statistics Education (pp. 35-51). Voorburg, The Netherlands: IOS Press.

Garfield, J. B., \& Ben-Zvi, D. (2008). Preparing school teachers to develop students' statistical reasoning. In C. Batanero, G. Burrill, C. Reading, \& A. Rossman (Eds.), Joint ICMI/IASE Study: Teaching Statistics in School Mathematics, Challenges for Teaching and Teacher Education. Proceedings of the ICMI Study 18 and 2008 IASE Roundtable Conference.

Ghani, S. A., \& Idris, U. P. S. (2009). Cooperative learning versus the lecture method of instruction in an introductory statistics course. Science and Mathematics Journal, 1(1), 5971.

Glencross, M., \& Binyavanga, K. (1996). The role of technology in statistics education: A view from a developing region. Proceedings of the 1996 IASE Round Table Conference. [Online: http://www.dartmouth.edu/ chance/teaching_aids/IASE/IASE.book.pdf ]

Hall, M. R., \& Rowell, G. H. (2008). Introductory statistics education and the National Science Foundation. Journal of Statistics Education, 16(2), 1-9.

[Online: http://www.amstat.org/publications/jse/v16n2/rowell1.pdf]

Hassan, S., Ismail, N., Ghazali, K., Gindana, C., \& Wan Jaafar, W. Y. (2011). Survey study on statistics anxiety: A case study using factor analysis. Paper presented at the $4^{\text {th }}$ International Conference on Science and Mathematics Education, Penang, Malaysia: SEAMEORECSAM.

Herrera, F. T. (2011). Problem and activity-based approaches: Their influences to students' achievement and retention scores in introductory probability and statistics. International Association of Multidisciplinary Research Journal, 2(1), 48-67.

Hong, K. S. (2002). Relationship between students' and instructional variables with satisfaction and learning from a web-based course. The Internet and Higher Education, 5(3), 267-281.

Hong, K. S., Lai, K. W., \& Holton, D. (2001). Web based learning environments: Observations from a web based course in a Malaysian context. Australian Journal of Educational Technology, 17(3), 223-243.

Jala, L .L., \& Reston, E. (2010). Graduate students' conceptions of statistical inference: Philippine perspective. In C. Reading (Ed.), Data and context in statistics education: Towards an evidence-based society. Proceedings of the $8^{\text {th }}$ International Conference on Teaching Statistics. Voorburg, The Netherlands: International Statistical Institute. [Online: http://iase-web.org/documents/papers/icots8/ICOTS8 10C1_JALA.pdf]

Kor, L. K., \& Lim, C. S. (2004). Learning statistics with graphics calculator: Students' viewpoints. Integrating Technology in the Mathematical Sciences (pp. 69-78) USM Proceedings Series. Pulau Pinang, Malaysia: Penerbit Universiti Sains Malaysia.

Limjuco, R. P. (2012). The use of platonic solids in probability concepts. IAMURE: International Journal of Mathematics, Engineering and Technology, 4(1), 1-17.

[Online: http://iamure.com/publication/index.php/ijmet/article/view/416] 
Link, W. C. (2002). An examination of student mistakes in setting up hypothesis testing problems. Louisiana-Mississippi Section of the Mathematical Association of America. [Online: http://www.sections.maa.org/lams/proceedings/spring2002/conway.link.pdf ]

MacGillivray, H., \& Pereira-Mendoza, L. (2011). Teaching statistical thinking through investigative projects. In C. Batanero, G. Burrill, \& C. Reading (Eds.), Teaching statistics in school mathematics - Challenges for teaching and teacher education: A Joint ICMI/IASE Study (pp. 109-120). Springer Science +Business Media.

Metz, M. L. (2010). Using GAISE and NCTM standards as frameworks for teaching probability and statistics to pre-service elementary and middle school mathematics teachers. Journal of Statistics Education, 18(3), 1-27.

[Online: http://www.amstat.org/publications/jse/v18n3/metz.pdf]

Mohamed, H., Sahari, N., Judi, H. M., \& Wook, T. M. T. (2012). Factors affecting FTSM students' achievement in statistics course. Procedia Social and Behavioral Sciences, 59, $125-129$.

Prado, M. M., \& Gravoso, R. S. (2011). Improving high school students' statistical reasoning skills: A case of applying anchored instruction. The Asia-Pacific Education Researcher, 20(1), 61-72.

Reston, E. (2005). Assessing statistical literacy in graduate level statistics education. Proceedings of the 55th Session of the International Statistical Institute, Sydney, Australia. [Online: www.iase-web.org/documents/papers/isi55/Reston.pdf ]

Reston, E. (2007). Models of student learning in graduate statistics education: towards statistical literacy and research competence. Proceedings of the $56^{\text {th }}$ Session of the International Statistical Institute (ISI), Lisbon, Portugal.

Reston, E. (2012). An outcome-based framework for technology integration in higher education statistics curricula for non-majors. Philippine context. Proceedings of the 2012 Roundtable Conference of the International Association for Statistical Education (IASE). Cebu City, Philippines.

Reston, E., \& Bersales, L. G. (2011). Reform efforts in training mathematics teachers to teach statistics: Challenges and prospects. In C. Batanero, G. Burrill, \& C. Reading (Eds.), Teaching Statistics in School Mathematics - Challenges for Teaching and Teacher Education: A Joint Study ICMI/IASE Study Book. Heidelberg: Springer.

Reston, E., Jala, L. L., \& Edullantes, T. (2006). Probing college statistics teachers' instructional goals and classroom practices within a statistical literacy framework. Proceedings of the $7^{\text {th }}$ International Conference on Teaching Statistics. Salvador, Bahia. Brazil: International Association for Statistical Education. [Online: http://iase-web.org/documents/papers/icots7/5A4 REST.pdf]

Rossman, A. J.. \& Short, T. H. (1995). Conditional probability and education reform: are they compatible? Journal of Statistics Education, 3(2). [Online: http://www.amstat.org/publications/jse/v3n2/rossman.html]

Rumsey, D. J. (2002). Statistical literacy as a goal for introductory statistics courses. Journal of Statistics Education, 10(3).

[Online: www.amstat.org/publications/jse/v10n3/rumsey2.html ]

Schau, C. (2003). Students' attitudes: The other important outcome in statistics education. Paper presented at the Joint Statistical Meetings of the American Statistical Association (pp. 3673-3683) San Diego, CA. [Online: http://www.statlit.org/pdf/schauasa.pdf]

Smith, N., Reid, A., \& Petocz, P. (2009). Representations of internationalisation in statistics education. Journal of Statistics Education, 17(1), 1-16. [Online: www.amstat.org/publications/jse/v17n1/smith.pdf ]

Tabunda, A. (2006). Some aspects of the teaching of statistics in the Philippines. The Philippine Statistician, 55(3-4), 43-54.

Tawil, N. M., Ismail, N. A., Asshaari, I., Osman, H., Nopiah, Z. M., \& Zaharim, A. (2011). Comparing lecture and e-learning process in mathematics and statistics courses for engineering students in Universiti Kebangsaan Malaysia. Procedia Social and Behavioral Sciences, 60, 420-425. 
Tawil, N. M., Ismail, N. A., Asshaari, I., Osman, H., Nopiah, Z. M., \& Zaharim, A. (2012). Learning process in mathematics and statistics courses towards engineering students: elearning or traditional method. Asian Social Science, 8(16), 128-133.

Tishkovskaya, S., \& Lancaster, G. (2012). Statistical education in the 21st Century: A review of challenges, teaching innovations and strategies for reform. Journal of Statistics Education, 20(2), 1-24.

Verschut, A., \& Bakker, A. (2010). Towards evaluation criteria for coherence of a data-based statistics curriculum. In C. Reading (Ed.), Data and context in statistics education: Towards an evidence-based society. Proceedings of the $8^{\text {th }}$ International Conference on Teaching Statistics. Voorburg, The Netherlands: International Statistical Institute. [Online: http://iase-web.org/documents/papers/icots8/ICOTS8 3E1 VERSCHUT.pdf]

Wallman, K. K. (1993). Enhancing statistical literacy: enhancing our society. Journal of the American Statistical Association, 88(421), 1-8.

Watson, J., \& Callingham, R. (2003). Statistical literacy: A complex hierarchical construct. Statistics Education Research Journal, 2(3), 3-46. [Online: http://iase-web.org/documents/SERJ/SERJ2(2)_Watson_Callingham.pdf]

Zanzali, N. A. A. (n.d.). Designing the mathematics curriculum in Malaysia: Making mathematics more meaningful. [Online: www.math.unipa.it/ grim/Jzanzali.PDF ]

Zanzali, N. A. A. (2003). Implementing the intended mathematics curriculum: Teachers' beliefs about the meaning and relevance of problem solving. In Proceedings of the International Conference, The Decidable and the Undecidable in Mathematics Education (pp. 34-37). Brno, Czech Republic.

Zieffler, A., Garfield, J., delMas, R., Le, L., Isaak, R., Bjornsdottir, A., \& Park, J. (2011). Publishing in SERJ: An analysis of papers from 2002-2009. Statistics Education Research Journal, 10(2), 5-26.

[Online: http://iase-web.org/documents/SERJ/SERJ10(2)_Zieffler.pdf]

ENRIQUETA RESTON

Science and Mathematics Education Department University of San Carlos-Talamban Campus Cebu City, Philippines 